\title{
A Human Physiologically-based Bio-kinetic Model for Cadmium
}

\section{Danjuma Dan-Adam Maza ${ }^{*}$, Stephen Friday Olukotun, Grace Olubunmi Akinlade}

Department of Physics and Engineering Physics, Obafemi Awolowo University, Ile-Ife, Nigeria

Email address:

mazadd@oauife.edu.ng (D. Dan-Adam M.), olukotunsf@oauife.edu.ng (S. F. Olukotun), gakinlade@oauife.edu.ng (G. O. Akinlade)

${ }^{*}$ Corresponding author

\section{To cite this article:}

Danjuma Dan-Adam Maza, Stephen Friday Olukotun, Grace Olubunmi Akinlade. A Human Physiologically-based Bio-kinetic Model for Cadmium. American Journal of Mathematical and Computer Modelling. Vol. 6, No. 1, 2021, pp. 9-13. doi: 10.11648/j.ajmcm.20210601.12

Received: January 14, 2021; Accepted: January 22, 2021; Published: February 9, 2021

\begin{abstract}
A physiologically-based bio-kinetic (PBBK) model, capable of simulating the absorption, distribution, and elimination of cadmium in humans has been developed. The formulation of this model was based on human data cleaned from literature. The liver, kidney, lung, artery, vein, stomach, small intestine and remainder of the body (other tissues not modelled explicitly) were modelled as compartments. While transfer rate coefficients were used to describe the kinetics of cadmium in the gastrointestinal track, the model used blood flow rates and partition coefficients rather than the traditional transfer rate coefficients to describe the distribution and accumulation of the chemical into critical organs such as liver, kidney and remainder of the body. A perfusion rate-limited kinetics model was assumed for these critical organs, where each of these tissues was regarded as a well-stirred compartment, without any concentration gradient within the compartment. The partition coefficients for critical organs modelled, along with transfer rate coefficients describing oral ingestion and inhalation were estimated by fitting the simulated concentration of cadmium in the liver, kidney and urine to observed concentrations found in literature. The model was capable of simulating, to a good degree of success, the results of empirical observations and other simulations found in literature. Simulations by the model also indicate that the partition coefficient of cadmium for the kidney, liver and other critical organs was higher in smokers.
\end{abstract}

Keywords: Physiologically-based, Bio-kinetic, Model, Cadmium, Simulation

\section{Introduction}

Cadmium is a naturally occurring trace element, belonging to the group IIB of the periodic table. Cadmium finds wide application in several industrial processes [1-4], however, it has no physiological function in the human body [2]. Cadmium is a heavy metal, whose presence in the environment has long been regarded as a source of health concern to humans and other forms of life [2, 4-9]. The toxic effects of cadmium spans across many organs [5]. Once absorbed in the body, cadmium accumulates in critical organs such as the liver and bone, and particularly in the kidney, where it has a long biological half-life of about 10-30 years [10]. The association of low levels of cadmium exposure to mortality are not well documented, however, studies have associated exposure to relatively high levels of cadmium to an increased risk of cancer, cardiovascular, related mortality [11].

In environmental health risk assessment of environmental pollutants, there is the need to relate internal dose to external exposure [12], a task that physiologically-based bio-kinetic models are well adapted for. Physiologically-based bio-kinetic models, under diverse exposure conditions and scenarios, can predict the target tissue dose of toxic chemicals and their metabolite, as a result have become useful tools in environmental health risk assessment of toxic materials [13].

A number of models have been developed to simulate the absorption, distribution, metabolism and elimination of cadmium in humans, however, to the best of our knowledge, none employed blood flow rates to the organs (compartments). The present effort is geared towards the development of a physiologically-based bio-kinetic model for cadmium, using blood flow rates to critical organs, rather than the traditional transfer rate coefficients. The model is intended for the simulation of the absorption, distribution and elimination of cadmium in humans. The model is not intended as a generic model for other chemicals. Furthermore, this study shall rely 
on published work of other researchers for data, for the purpose of comparison and evaluation.

\section{Materials and Methods}

Materials used in this study were Python software environment, Graph data extractor. Experimental observations used in evaluating the model were mainly from the work of [14-17]. Where these empirical observations and simulations were presented in graphical form, they were extracted using a software, Graph data extractor.

\subsection{Model Description and Development}

The model was structured as shown in Figure 1. The model consists of eight compartments (liver, kidney, lung, remainder of the body, vein, artery, stomach, and small intestine). Two mathematical delays $\left(A_{x}\right.$ and $\left.A_{a}\right)$ were inserted into the model. The mathematical delays, $A_{x}$ and $A_{a}$, account for the piecemeal nature of oral ingestion and inhalation of the chemical, respectively. Physiological parameters, namely; body weight and cardiac output for the respective age groups were gleaned from the published work [18, 19]. The volume of the various compartments and their respective blood flow rates were calculated as fractions of the body weight and cardiac output, respectively (Table 1).

Table 1. Physiological Parameters.

\begin{tabular}{ll}
\hline Tissue volumes & \\
\hline Tissue & Fractional volume \\
\hline Liver & 0.026 \\
Kidney & 0.004 \\
Gut & 0.017 \\
Lung & 0.007 \\
Remainder of the body & 0.967 \\
Blood flow & \\
Tissue & Fractional flow \\
Liver & 0.046 \\
Kidney & 0.175 \\
Gut & 0.181 \\
Remainder of the body & 0.598 \\
\hline
\end{tabular}

Cardiac output, $Q_{C}$, was calculated as:

$$
Q_{C}=Q_{C C} B_{w}^{0.75}
$$

where $Q_{C C}=16.4 \mathrm{Lh}^{-1}$ (for adults), and $B_{W}$ is the body weight in kilograms $(\mathrm{kg})$.

Total blood volume was estimated as 0.065 of body weight, while the vein and artery compartments were allocated $70 \%$ and $30 \%$ of the blood volume, respectively. Orally ingested cadmium was modelled as passing through the stomach and the small intestine before absorption via the gut into the circulation (Figure 1). The transfer rate coefficients $k_{x}, k_{0}$, $k_{1}$ and $k_{2}$, describe the kinetics of cadmium in the gastrointestinal track. The uptake and excretion of ingested cadmium, were modelled by the transfer rate coefficients $k_{1}$ and $k_{2}$, respectively. Uptake of ingested cadmium was modelled as entering the circulation through the gut. For inhaled cadmium, a fraction, $f_{2}$, enters the circulation through the lung.

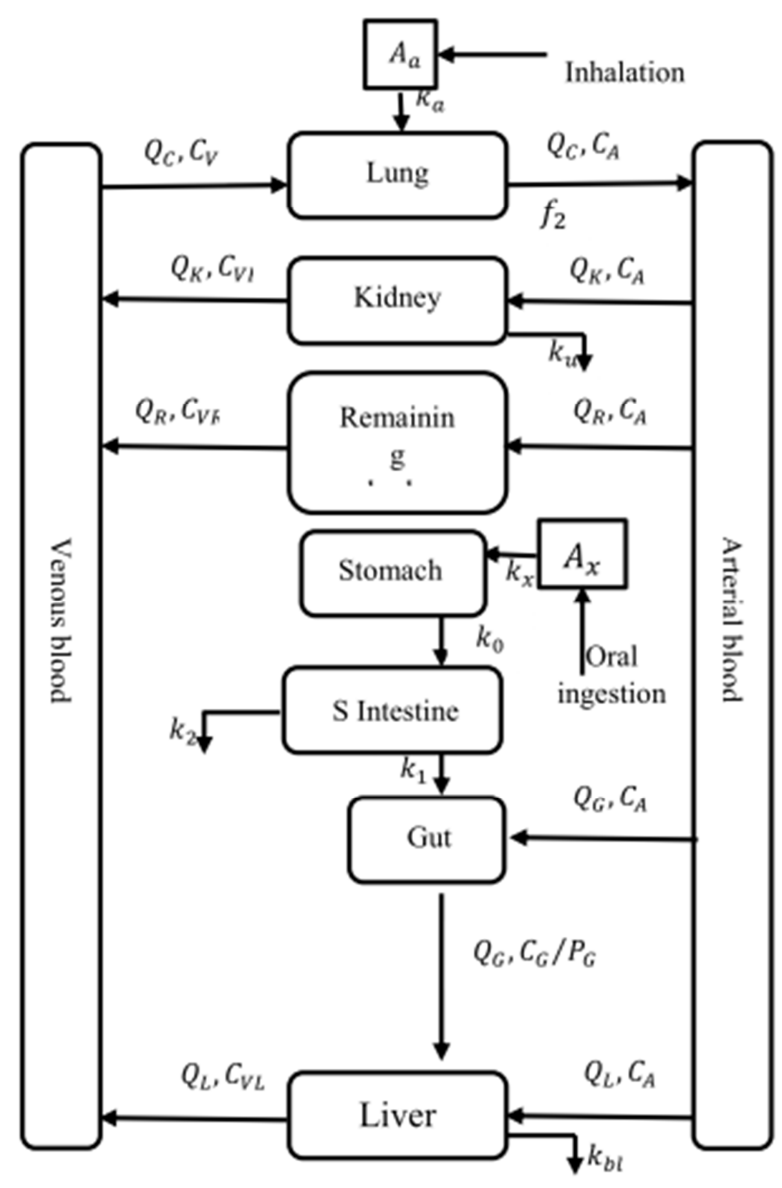

Figure 1. Model structure.

Table 2. Partition coefficients and transfer coefficients.

\begin{tabular}{|c|c|c|c|}
\hline \multicolumn{4}{|c|}{ Partition coefficients } \\
\hline Symbol & Compartment & $\begin{array}{l}\text { Chronic } \\
\text { exposure }\end{array}$ & $\begin{array}{l}\text { Acute } \\
\text { exposure }\end{array}$ \\
\hline$P_{l}$ & Liver & 1000 & 1500 \\
\hline$P_{k}$ & Kidney & 2000 & 2500 \\
\hline$P_{l u}$ & Lung & 2.0 & 2.0 \\
\hline$P_{g}$ & Gut & 1.0 & 1.0 \\
\hline$P_{r}$ & Remainder of the body & 1000 & 1000 \\
\hline \multicolumn{4}{|c|}{ Transfer Coefficients } \\
\hline Symbol & Description & Value $\left(h^{-1}\right)$ & \\
\hline$k_{x}$ & $\begin{array}{l}\text { Coefficient regulating piecemeal } \\
\text { ingestion }\end{array}$ & 0.000015 & 0.00015 \\
\hline$k_{0}$ & $\begin{array}{l}\text { Coefficient from stomach to small } \\
\text { intestine }\end{array}$ & 0.000015 & 0.0035 \\
\hline$k_{1}$ & $\begin{array}{l}\text { Coefficient from small intestine to } \\
\text { gut }\end{array}$ & 0.0015 & 0.015 \\
\hline$k_{2}$ & Fecal excretion rate & 0.7 & 0.07 \\
\hline$k_{b l}$ & Biliary excretion rate & $0.1-0.3$ & 0.0005 \\
\hline$k_{u}$ & Urinary excretion rate & $0.017-0$. & 0.0255 \\
\hline$k_{h}$ & Hair excretion rate & 0.009 & 0.009 \\
\hline$k_{a}$ & $\begin{array}{l}\text { Coefficient regulating piecemeal air } \\
\text { intake }\end{array}$ & 0.00000072 & \\
\hline$f_{2}$ & Fraction absorbed via inhalation & 0.00025 & \\
\hline
\end{tabular}

Blood flow rates instead of the conventional transfer rate coefficients were used to describe the kinetics of the chemical to critical organs such as the liver, kidney, lung and the remainder of the body. A perfusion rate-limited model was assumed for liver, kidney, lung, and remainder of the body. Each of these tissues was regarded as a single well-stirred 
compartment, without any concentration gradient of the chemical within the compartment. The concentration-time profile in these tissues was assumed to be controlled by the blood flow to these compartments and their respective partition coefficients.

The flow of cadmium in and out of a non-excretion compartment, $i$, is described by a mass balance equation as follows:

$$
\frac{d C_{i}}{d t}=Q_{i}\left(C_{A}-C_{V i}\right) / V_{i}
$$

Where $Q_{i}$ is the blood flow rate to the compartment, $C_{A}$ is the concentration in arterial blood entering the compartment, $V_{i}$ is the volume of compartment, while $C_{V i}$ (given as $\frac{C_{i}}{P_{i}}$ ) is the concentration of cadmium in the venous blood exiting the compartment. $C_{i}$ and $P_{i}$ are the concentration and partition coefficient of the chemical in the specified compartment, respectively.

For compartments involved in excretion of cadmium, the kinetics of the chemical is described as follows:

$$
\frac{d C_{i}}{d t}=Q_{i}\left(C_{A}-\frac{C_{i}}{P_{i}}\right) / V_{i}-\left(k_{e} \frac{C_{i}}{P_{i}}\right) / V_{i}
$$

where $k_{e}$ is the excretion rate coefficient.

Table 3. Mass balance differential equations describing the concentration or

\begin{tabular}{|c|c|}
\hline Compartment & Equation \\
\hline Vein & $\begin{array}{c}\frac{d C_{v}}{d t}=\left(Q_{O T} \frac{C_{O T}}{P_{O T}}+\left(Q_{L}+Q_{G}\right) \frac{C_{L}}{P_{L}}+Q_{K} \frac{C_{K}}{P_{K}}+k_{v} A_{v}\right. \\
\left.-Q_{C} C_{V}\right) / V_{v e i n}\end{array}$ \\
\hline Lung & $\frac{d C_{L U}}{d t}=Q_{c}\left(C_{V}-\frac{C_{L U}}{P_{L U}}\right) / V_{\text {vein }}+f_{2} k_{a} A_{a} / V_{\text {vein }}$ \\
\hline Artery & $\frac{d C_{A}}{d t}=Q_{C}\left(C_{L u}-C_{A}\right) / V_{a r t}$ \\
\hline Liver & $\frac{d C_{L}}{d t}=\frac{Q_{L}\left(C_{A}-\frac{C_{L}}{P_{L}}\right)}{V_{L}}-k_{b l} C_{L} / V_{L}$ \\
\hline Kidney & $\frac{d C_{K}}{d t}=\frac{Q_{K}\left(C_{A}-\frac{C_{K}}{P_{K}}\right)}{V_{K}}-k_{r} C_{K} / V_{K}$ \\
\hline Urine & \\
\hline $\begin{array}{l}\text { Remainder of the } \\
\text { body }\end{array}$ & $\frac{d C_{O T}}{d t}=Q_{O T}\left(C_{A}-\frac{C_{O T}}{P_{O T}}\right) / V_{O T}-k_{h} C_{O T} / V_{O T}$ \\
\hline $\begin{array}{l}\text { Mathematical } \\
\text { delay }\end{array}$ & $\frac{d A_{x}}{d t}=$ Oraldose $-k_{x} A_{x}$ \\
\hline Stomach & $\frac{d A_{S T}}{d t}=k_{x} A_{x}-k_{0} A_{S T}$ \\
\hline Small intestine & $\frac{a A_{S I}}{d t}=k_{0} A_{S T}-k_{1} A_{S I}-k_{2} A_{S I}$ \\
\hline Gut & $\frac{d C_{G}}{d t}=k_{1} A_{S I} / V_{G}+Q_{G}\left(C_{A}-\frac{C_{G}}{P_{G}}\right) / V_{G}$ \\
\hline Liver & $\begin{array}{c}\frac{\mathrm{dC}_{\mathrm{L}}}{\mathrm{dt}}=\left({ }^{\mathrm{Q}_{\mathrm{G}} \mathrm{C}_{\mathrm{G}} / \mathrm{P}_{\mathrm{G}}}+\mathrm{Q}_{\mathrm{L}} \mathrm{C}_{\mathrm{A}}-\left(\mathrm{Q}_{\mathrm{G}}+\mathrm{Q}_{\mathrm{L}}\right) \mathrm{C}_{\mathrm{L}} / \mathrm{P}_{\mathrm{L}}\right) / \mathrm{V}_{\mathrm{L}} \\
-\mathrm{k}_{\mathrm{bl}} \mathrm{C}_{\mathrm{L}} / \mathrm{V}_{\mathrm{L}}\end{array}$ \\
\hline
\end{tabular}
amount of cadmium in the compartments.

The partition coefficients and transfer rate coefficients employed in the model were chosen by trying several alternatives to determine the set (Table 2) that gave the best fit to data gleaned from literature. As shown in Table 2, two sets of parameters were employed in this modelling effort, one set for long term, chronic, exposure and another set for short term, acute, bolus exposure to cadmium.
The concentration of cadmium in the respective compartments was calculated by solving numerically, a series of mass balance differential equations (Table 3). Python software environment was employed to develop the model used to describe the absorption distribution and elimination of cadmium in the human body.

\subsection{Simulations}

To evaluate the performance of the current model, the results of some experimental observations and other simulations found in literature were simulated. Results of researches conducted by a host of other researchers [14, 15, 17] and a simulation by [16] were simulated using the model developed in this study.

In a study conducted by Perama and collaborators using synthetic gastrointestinal fluids, the concentration of cadmium in gastrointestinal fluids were simulated and measured [14]. It was a short term simulation using a bolus dose of $0.75 \mathrm{mg} / \mathrm{kg}$. In simulating the work of Perama and cohorts, the transfer coefficients $k_{x}, k_{0}, k_{1}$ and $k_{2}$ used in simulating long term exposure to cadmium (Table 2.) had to be altered. Consequently, $k_{x}, k_{0}, k_{1}$ and $k_{2}$ were assigned the values $0.00015 h^{-1}, 0.0035 h^{-1}, 0.015 h^{-1}$ and $0.07 h^{-1}$, respectively. An oral bolus dose of $0.75 \mathrm{mg} / \mathrm{kg}$, (same as the Perama study) was inserted as input.

The autopsy studies carried out on Swedish citizens by Elinder et al., measuring the concentration of cadmium in kidney cortex was simulated using $16.0 \mu \mathrm{g}$ daily oral intake of cadmium for non-smokers and an additional intake of 3 $\mu \mathrm{g} /$ day through inhalation for smokers [17]. The onset of smoking was assumed to be at 20 years of age.

The model developed by Nordberg and Kjellstrom simulated the concentration of cadmium in the kidney cortex and liver of battery factory workers exposed to industrial air $[15,16]$. Employing the present model, the concentration of cadmium in the kidney cortex and liver of battery factory workers exposed to industrial air containing $50 \mu \mathrm{g} / \mathrm{m}^{3}$ was simulated.

Furthermore, the Nordberg and Kjellstrom model also simulated the concentration of cadmium in various tissues of a 45 years old Japanese resident of Tokyo. Using, as input, cadmium intake of $40 \mu \mathrm{g}$ and $2.7 \mu \mathrm{g}$ via food and air, respectively, the current model simulated the concentration of cadmium in various tissues of this 45 years old Japanese resident of Tokyo.

\section{Results and Discussions}

\subsection{Results}

The result of simulations by the present model are compared with some experimental observations found in literature and presented in Figure 2 to Figure 4 and in Table 4. While Figure 2 compares the experiment conducted by [14] with the simulation by the present model. Figure 3 is a comparison of a Swedish autopsy studies [17] and the current model simulation. On the other hand, Figure 4 compares a 
simulation by the present model and the result of a study conducted on battery factory workers $[15,16]$. Table 4 compares our model calculations and empirical observations conducted on a Tokyo resident.

\subsection{Discussions}

The simulation by the present model of concentration of cadmium in the small intestine compares favorably with the experiment of Perama and co-researchers [14]. In the experiment conducted by Perama and cohorts, using synthetic gastrointestinal fluids, the concentration of cadmium in gastrointestinal fluids were simulated and measured [14]. An oral bolus input of $0.75 \mathrm{mg} / \mathrm{kg}$ was used. A comparison of the experimental observation and the simulation by the present model, following an oral bolus dose of $0.75 \mathrm{mg} / \mathrm{kg}$ shows a reasonable agreement (Figure 2).

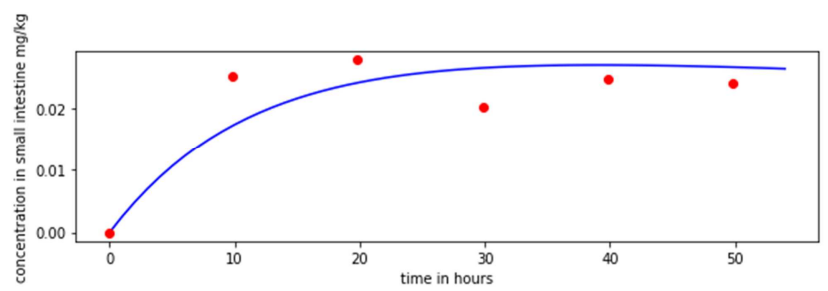

Figure 2. Concentration of cadmium $(\mathrm{mg} / \mathrm{kg}$ ) in the small intestine following an oral bolus dose of $0.75 \mathrm{mg} / \mathrm{kg}$ : The bullets points are experimental observations [14], while the solid line is the simulation by the present model.

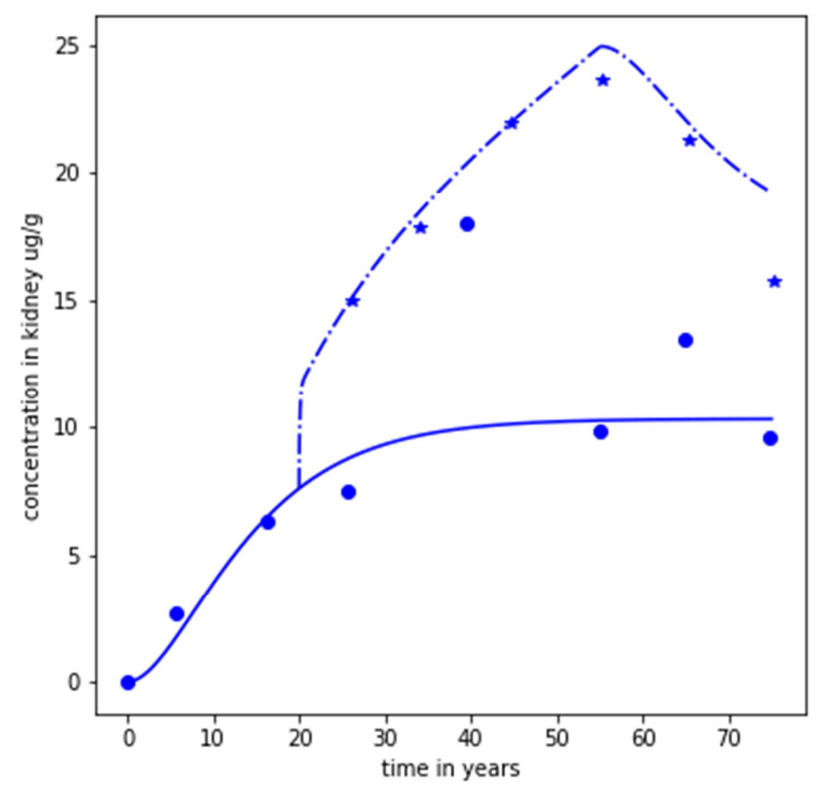

Figure 3. Simulated and empirically determined concentrations in kidney cortex of Swedish citizens: The solid (_ and dashed (---) lines represent the simulation from the present model for non-smokers and smokers respectively, while the stars (*) and crosses (+) are empirical observations [17] for non-smokers and smokers, respectively.

There is a reasonable agreement between an autopsy studies conducted by Elinder and cohorts with model simulations from the model developed in this study [17]. In the autopsy studies by Elinder and collaborators, the concentration of cadmium in the kidney cortex of some Swedish citizens were empirically measured [17]. Figure 3 compares the result of that study and the simulation, using the current model, of concentration of cadmium in adults having a daily intake of $16.0 \mu \mathrm{g} /$ day of cadmium. The upper curves are for smokers assumed to be smoking 20 cigarettes per day, corresponding to an additional intake of $3 \mu \mathrm{g} /$ day of cadmium via inhalation. It is worth mentioning that in simulating the concentration of cadmium in the kidney cortex of smokers (Figure 3), the partition coefficient for kidney and other critical organs had to be adjusted upwards. This Suggest that in the kidney and other critical organs, where cadmium is retained significantly, smoking does not only increase the daily intake of cadmium, it equally enhances the retention capability of the chemical, with its attendant impact on several organs. However, the mechanism through which this is achieved remains unknown.

A comparison of simulations by the current model and the simulation of the model by Nordberg and Kjellstrom, of the concentration of cadmium in the kidney cortex and liver of battery factory workers exposed to industrial air containing 50 $\mu \mathrm{g} / \mathrm{m}^{3}$ of cadmium from age $20-60$ is shown in Figure4 [15, $16]$.

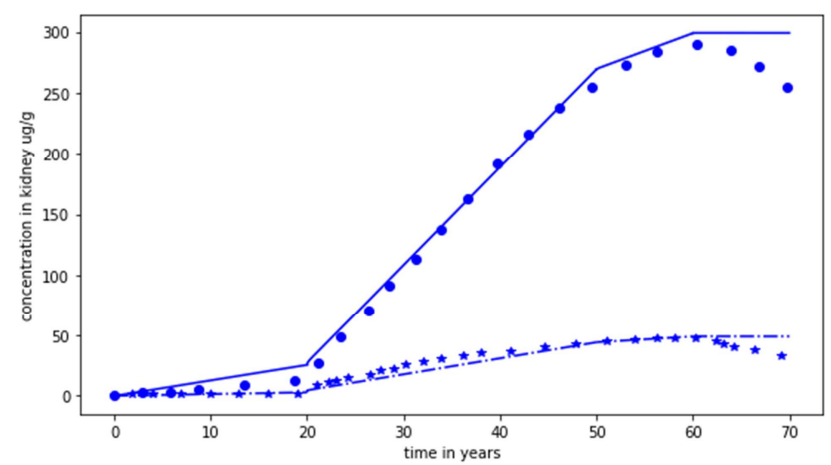

Figure 4. Comparison of simulations from the present model and simulations from Nordberg and Kjellstrom model of the concentration of cadmium in the kidney cortex and liver of a Swedish factory worker exposed to industrial air containing $50 \mu \mathrm{g} / \mathrm{m}^{3}$ of cadmium from age 20 - 60. Kidney cortex: Present model simulation (solid line), Nordberg and Kjellstrom model simulation (bullet); Liver: Present model simulation (dash dot), Nordberg and Kjellstrom model simulation (star)

Furthermore, empirically determined concentrations of cadmium in various tissues of a 45 years old Japanese resident of Tokyo with a daily cadmium intake of $40 \mu \mathrm{g}$ and $2.7 \mu \mathrm{g}$ via food and air [16] compares favorably with model calculations using the present model (Table 4).

The predictions (Figure 2, Figure 3, and Table 4) from the current model, fitted reasonably the experimental observations of Perama and cohorts, Nordberg and Kjellstrom, and Elinder et al. [14, 16, 17]. The present model also simulated (Figure 4) to a reasonable degree of agreement the simulation by the model constructed by Nordberg and Kjellstrom [16]. 
Table 4. Empirical and calculated concentration of cadmium in various tissues for a 45 years old Japanese resident of Tokyo with a daily cadmium intake of $40 \mu \mathrm{g}$ and $2.7 \mu \mathrm{g}$ via food and air respectively.

\begin{tabular}{lll}
\hline \multirow{2}{*}{ Tissue } & \multicolumn{2}{l}{ Cadmium concentration $(\boldsymbol{\mu g} / \mathbf{g})$} \\
\cline { 2 - 3 } & Observed & Simulated \\
\hline Kidney & 65 & 58 \\
Liver & 3.4 & 3.53 \\
Other Tissues & 0.2 & 0.21 \\
Urine & 1.1 & 1.2 \\
\hline
\end{tabular}

\section{Conclusion}

A cadmium physiologically-based bio-kinetic model utilizing blood flow rates and partition coefficients to critical organs was developed for humans. This model could simulate, the absorption, distribution, metabolism and elimination (ADME) properties of cadmium. The predictions from the current model, agrees reasonably with experimental observations and simulations by other researchers $[14,16,17]$. The study further concludes that smoking increases the retention of cadmium in tissues by inducing an enhanced partition coefficient, however, the mechanism by which this happens remains unknown. It is believed that this model could be adapted as a tool in environmental health risk assessment of cadmium.

\section{Acknowledgements}

The authors would like to thank Professor J. O. Ojo of the Department of Physics and Engineering Physics, Obafemi Awolowo University, Ile-Ife for his supporting role.

\section{References}

[1] Greenberg, S. R., 1979. Cadmium toxicity. Lancet: 1242, Doi: 10.1136/jcp.32.10.1073-c.

[2] Godt, J., Scheidig, F., Grosse-Siestrup, C., Esche, V., Brandenburg, P., Reich, A., et al., 2006. The toxicity of cadmium and resulting hazards for human health. Journal of Occupational Medicine and Toxicology 1 (1): 1-6, Doi: 10.1186/1745-6673-1-22.

[3] Bernhoft, R. A., 2013. Cadmium toxicity and treatment. The Scientific World Journal 2013: 1-7, Doi: 10.1155/2013/394652.

[4] Nordberg, G. F., Bernard, A., Diamond, G. L., Duffus, J. H., Illing, P., Nordberg, M., et al., 2018. Risk assessment of effects of cadmium on human health (IUPAC Technical Report). Pure and Applied Chemistry 90 (4): 755-808, Doi: 10.1515/pac-2016-0910.

[5] Satarug, S., Garrett, S. H., Sens, M. A., Sens, D. A., 2010. Cadmium, environmental exposure, and health outcomes. Environmental Health Perspectives: 182-90, Doi: 10.1289/ehp.0901234.

[6] Rahimzadeh, M. R., Rahimzadeh, M. R., Kazemi, S., Moghadamnia, A. A., 2017. Cadmium toxicity and treatment: An update. Caspian Journal of Internal Medicine: 135-45, Doi: 10.22088/cjim.8.3.135.
[7] Satarug, S., 2018. Dietary cadmium intake and its effects on kidneys. Toxics 6 (1): 1-23, Doi: 10.3390/toxics6010015.

[8] Ali, H., Khan, E., Ilahi, I., 2019. Environmental chemistry and ecotoxicology of hazardous heavy metals: Environmental persistence, toxicity, and bioaccumulation. Journal of Chemistry: 1-15, Doi: 10.1155/2019/6730305.

[9] Andjelkovic, M., Djordjevic, A. B., Antonijevic, E., Antonijevic, B., Stanic, M., Kotur-Stevuljevic, J., et al., 2019. Toxic effect of acute cadmium and lead exposure in rat blood, liver, and kidney. International Journal of Environmental Research and Public Health 16 (2): 1-21, Doi: 10.3390/ijerph16020274.

[10] Järup, L., 2002. Cadmium overload and toxicity. Nephrology Dialysis Transplantation 17 (suppl_2): 35-9, Doi: 10.1093/ndt/17.suppl_2.35.

[11] Menke, A., Muntner, P., Silbergeld, E. K., Platz, E. A., Guallar, E., 2009. Cadmium levels in urine and mortality among U.S. adults. Environmental Health Perspectives 117 (2): 190-6, Doi: 10.1289/ehp.11236.

[12] Béchaux, C., Bodin, L., Clémençon, S., Crépet, A., 2014. PBPK and population modelling to interpret urine cadmium concentrations of the French population. Toxicology and Applied Pharmacology 279 (3): 364-72, Doi: 10.1016/j.taap.2014.06.026.

[13] Andersen, M. E., 2003. Toxicokinetic modeling and its applications in chemical risk assessment. Toxicology Letters 138 (1-2): 9-27, Doi: 10.1016/S0378-4274(02)00375-2.

[14] Perama, Y. M. I., Rashid, N. S. A., Fadzil, S. M., Siong, K. K., 2018. Absorption, distribution and elimination behaviours of cadmium treated by in vitro DIN from WLP residue using SAAM II modeling. Sains Malaysiana 47 (3): 611-8, Doi: 10.17576/jsm-2018-4703-23.

[15] Kjellström, T., Nordberg, G. F., 1978. A kinetic model of cadmium metabolism in the human being. Environmental $\begin{array}{llll}\text { Research } & 16 & (1-3): & 248-69,\end{array}$ 10.1016/0013-9351(78)90160-3.

[16] Nordberg, G. F., Kjellstrom, T., 1979. Metabolic model for cadmium in man. Environmental Health Perspectives Vol. 28 (February): 211-7, Doi: 10.2307/3428923.

[17] Elinder, C.-G., Kjellström, T., Friberg, L., Linnman, B. L. L., 1976. Cadmium in Kidney Cortex, Liver, and Pancreas from Swedish Autopsies. Archives of Environmental Health: An International Journal 31 (6): 292-302, Doi: 10.1080/00039896.1976.10667239.

[18] Haddad, S., Restieri, C., Krishnan, K., 2001. CHARACTERIZATION OF AGE-RELATED CHANGES IN BODY WEIGHT AND ORGAN WEIGHTS FROM BIRTH TO ADOLESCENCE IN HUMANS. Journal of Toxicology and Environmental Health, Part A 64 (6): 453-64, Doi: $10.1080 / 152873901753215911$.

[19] Price, K., Haddad, S., Krishnan, K., 2003. Physiological Modeling of Age-Specific Changes in the Pharmacokinetics of Organic Chemicals in Children. Journal of Toxicology and Environmental Health, Part A 66 (5): 417-33, Doi: $10.1080 / 15287390306450$. 